\title{
A case study of $2 \mathrm{~d} / 3 \mathrm{~d}$ cad virtual prototype simulation programs to enhance student performance in student-centered fashion design education
}

\begin{abstract}
To consider rapid development of advanced technology in the fashion industry, this study focuses on analyzing how 2D CAD patternmaking and 3D garment simulation programs have been used as tools for enhancing student performance in studentcentered fashion design education. A case study is used to capture students' perceptions while they are using 2D and 3D software for design development and measure student performance with respect to enhancement of understanding of 3D visualization in student-centered education. This study discovered that both 2D patternmaking and 3D simulation program usage increased and enhanced student learning and helped them be more efficient in their pattern development process. It was also found that both programs encouraged students to think critically about their design process. This study provides insight with respect to how fashion design classes can properly equip future professionals with new technology developments in the fashion industry.
\end{abstract}

Volume 3 Issue I - 2017

Ja Young Hwang,' Kim HY Hahn'
'The Fashion School, Kent State University, USA
${ }^{2}$ The Fashion School, Kent State University, USA

Correspondence: Ja Young Hwang, The Fashion School, College of Arts, Kent State University, PO Box 5190/515 Hilltop Drive, Kent, OH 44242, USA, Tel 3306720396, Fax 3306723772, Email jhwang5@kent.edu

Received: September 19,2017 | Published: October 12, 2017

Keywords: patternmaking, 3d, garment simulation, learning tool, cad design

\section{Introduction}

The apparel industry is one of the most globalized industries (Easters, 2012), so that industry and associated companies continually seek the fastest and most efficient approaches, including effective communication and fast prototyping technology, to support changes intended to speed up the design process. Consequently, computer technology has been a very hot topic in the clothing industry during recent years, and fashion companies cannot avoid inevitable adoption of computer technology. To enhance design and production performance, 2D computer aided design (CAD) programs, especially 2D patternmaking and 3D clothing design and modelling, have been considered necessary solutions for new product development processes (Santos, 2014), because such programs can enhance communication, ease flow, and produce cost effectiveness at all stages from design to production Chase. ${ }^{1}$ Use of such advanced technology is based on the assumption that the development of 2D and 3D technology will boost efficiency by letting designers quickly reiterate and change designs without waiting for product samples, saving time and money before actual product launches (Santos, 2014).

While digitization of the design process in the fashion industry has been moving somewhat slower than in many other industries, today's fashion designers have combined both analog and digital design processes, dramatically changing the fashion industry (Easters, 2012; Siersema, 2015). Previous research has predicted that design and production development will profoundly rely on development of technology and this has proven to be true (Kim and Johnson, 2007). For example, today's young fashion designers can develop their collections virtually and present their designs through a virtual world or social media and subsequently deliver a collection on demand (Sierema, 2015). During the past few years, production development has made design so simple that it can be done using a computer, and clothing companies are becoming heavily dependent on computer use and the general role of technology in that field.

Along with the development of $2 \mathrm{D}$ CAD programs for use in the clothing industry, 3D simulation programs have also been used as tools for enhancing student learning performance in medicine, architecture, product design, science, accessory design, automotive, and many other areas (Korakadis, Pavlatou, Palyvo, \& Spyrellis, 2009; Perdomo, Shiratuddin, Thabet, \& Ananth, 2005; Silen, Wirell, Kvist, Nylander \& Smedeby, 2008). However, using 3D modelling as a teaching enhancement tool in fashion design classes has progressed more slowly than in most other fields. Even though interest in 3D virtual modelling in the fashion industry has grown, it is difficult to find examples of previous research related to measuring student attitude or perceptions with respect to learning $3 \mathrm{D}$ garment simulation. Moreover, very few researchers have studied the broad implications of technology-integrated approaches such as 3D virtual modelling in student-centered (engaged) apparel education or 3D visualization as a tool for improving design education. Therefore, with technological development accelerating growth for changes in the future fashion industry, it is critical for educators to help students become equipped with proper digital technical skills, techniques, and knowledge, and arm them with knowledge of $2 \mathrm{D}$ and $3 \mathrm{D}$ computer-aided design technology processes and design thinking (Kim and Johnson, 2007).

\section{Need for 2D computer-aided design software}

Today's clothing industry is moving toward using advanced technology in designing and pattern-drafting. Clothing companies seek new solutions for saving time in product development and generally increasing efficacy in activities ranging from the design process through the manufacturing process among designers, manufacturers, and retailers (Siersema, 2015). 2D patternmaking software was first 
introduced to the market in the 1980s for enhancing speed, easing flow, and improving efficiency Chase. ${ }^{1}$ Examples of two-dimensional graphic software packages customized for the apparel industry include PDS (OptiTex), Accumark (Gerber) and Master Pattern Design (PAD system) Sayem, Kennon \& Clarke. ${ }^{2}$ Using such programs, users starting from scratch can draft patterns with simple geometric shapes; it is furthermore possible to use a digitizer to input existing block patterns into the system and create extensive archives for virtual use Sayem et al. ${ }^{2}$ A 2D CAD system allows for pattern drafting, sizing, nesting, and marker making for cutting/sewing garments Fontana et $\mathrm{al}^{3}$

The needs of $2 \mathrm{D}$ patternmaking software can be categorized in several ways. Puri ${ }^{4}$ describes the challenges of clothing companies facing the current situation as follows:

a. Customer demand for innovativeness in lesser time".

b. "Growing customer base".

c. "Increase pressure to reduce new product development costs".

d. "Decrease time for product development and shorten time-tomarket".

e. "Shrinking lead time for volumes".

f. "Cost management" (pg. 22-23)

The use of 2D patternmaking tools is effective in student-centered learning environment because it supports design flexibility. 2D CAD tools not only allow designers to directly create designs on a screen, they enhance student learning performances by enabling faster flow and allowing stylists "to store, retrieve, and modify images, patterns, colors, fabrics and shapes at will, to consult databases, and to display a complete design" Abecassus-Moedas. ${ }^{5} \mathrm{CAD}$ tools could also possibly increase and enhance student learning performance and creativity because they will save time by creating and drafting designs with a few clicks, thereby assisting students in creating and modifying their designs without going through drastic changes.

\section{D garment simulation or virtual prototyping}

The pressure of introducing more collections with shorter lead times has led to development of 3D technology tools in the fashion industry (Santos, 2014). The concept of 3D garment simulation or virtual prototyping modelling was first introduced in the 1980s Fontana, Rizzi, \& Cugini, ${ }^{3}$ and one of the early $3 \mathrm{D}$ garment simulation tools for clothing design was invented in the early 1990s Sayem, Kennon \& Clarke. $^{2}$

3D garment simulation could possibly act as a powerful tool for enhancing communication in the value chain, including designers, merchandisers, manufacturers, suppliers, and clients (Santos, 2014). 3D garment simulation could build bridges between everyone including technical designers, conceptual designers, and patternmakers, from marketing departments to suppliers and manufacturers from all over the world, by acting as a common language for everyone involved in this process (Lectra, 2014). Hence, more apparel companies, including Under Armour, Theory, Scoot sports, and not limited to designer brands such as Roberto Cavali are using 3D solution Optitex. ${ }^{6} \mathrm{~A}$ benefit of using $3 \mathrm{D}$ garment simulation is that the program will allow designers to test options, styles, and design ideas through virtual prototyping and simulation, enabling analysis before engaging in physical prototyping. This will save time because it reduces time spent creating much physical prototyping and allows designers freedom to go through multiple changes without creating physical prototypes Fontana et al. ${ }^{3}$ Puri; ${ }^{4}$ Sayem et al. ${ }^{2}$

As regards 3D garment simulation program, it can be used as a significant tool in design classes to test the fit, design concepts, and aesthetics of a garment allowing students to virtually test and prove the value of their ideas without need for making physical samples, representing a valuable design tool, especially in design studios where students learn design through project-based practice, i.e., 'Learning by doing', rather than through theoretical discourse. Both reflective practice and metacognition are crucial in learning design, and in this way, students have been better able to reflect on their own practice and make improvements during their subsequent stages of design.

\section{Use of 2D and 3D CAD programs in the classroom}

Previous research has examined how 3D CAD simulation influences student learning and the design process (Salman, 2011), with results indicating that detailed representation of $3 \mathrm{D} C \mathrm{CAD}$ simulations can dramatically change the design process, particularly for Architecture students. Investigating how 2D and 3D CAD programs can also contribute to student learning is critical in design classrooms, because student designers constantly learn by doing assignments or projects. Engaging in this design process could be a valuable learning experience for students to be prepared for the real world. With respect to developing a product, a 3D garment simulation program will support buyer validation without the need for making a physical sample, a highly-effective approach in terms of time and cost Puri. ${ }^{4}$

Previous research indicates that both students and faculty tend to concentrate on aesthetics in research and teaching, and teaching a 3D virtual model will help students to focus more on construction issues, helping them to more deeply understand construction technology Perdomo. ${ }^{7}$ Furthermore, 3D virtual modelling enhances the interactive design studio learning environment. Thus, in fashion design classes, the use of 3D virtual models in design education will enhance student learning through providing examples of fit and construction issues, a possibly even through experiences involving virtual simulation Haque, ${ }^{8}$ Perdomo et al.

Previous research has shown that 3D visualization as a learning tool has helped improve student learning and transfers a better understanding of learning with respect to subject matter (Peterson, Skinkvist, Wang, and Smedby, 2015). Perdomo et al. ${ }^{7}$ discuss the impact of using 3D technology and its advantages for architecture students over teaching approaches utilizing 2D representation only. That study also argues that 3D modeling is beneficial for helping students in conceptual understanding of subject matter. Students' attitudes toward using a 3D visualization program tool, when compared to traditional methods, especially textbooks, were also positive. The ability to observe and manipulate the form of 3D structures was an especially important advantage with respect to a learning environment using a 3D visualization tool in the classroom setting (Peterson, 2015). However, it would be difficult to conclude that this would be the same for fashion design students, as these studies are done with architecture and medical students.

We educators therefore must find answers to the following question: "What types of training are needed for fashion design students?" Kim \& Johnson (2007) predicted that rapid technology changes would lead educators to question the nature of fashion design education of future 
apparel designers. Thus, Grant, (2013), encourages use of various software packages, including 2D patternmaking and 3D garment simulation programs, to drive fashion student education, because this would enhance student meta-skills of "flexibility" and "adaptability" through use of the various tools and instruments. This idea is also supported by a previous research study describing evolution of 3D virtual prototyping and its influence on design processes and visual thinking (Sierema, 2015).

While much research related to student attitude towards virtual learning environments or virtual reality has been conducted Barkand \& Kush $;{ }^{9}$ Bronack; ${ }^{10}$ Huang; $;{ }^{11}$ Monahan, ${ }^{12}$ previous research on evaluation of a 3D virtual environment as an educational tool is very limited. Moreover, it is rare to find studies on student attitude and perception related to use of both $2 \mathrm{D} \mathrm{CAD}$ and $3 \mathrm{D}$ visual prototyping tools for fashion design development learning enhancement, so the following research questions have guided this research;

i. How does a 2D patternmaking program enhance student learning outcomes?

ii. How does a 3D garment simulation program enhance student-learning outcomes?

iii. What are students' perceptions of using $2 \mathrm{D}$ and $3 \mathrm{D}$ CAD programs for fashion design development?

iv. How can fashion design classes prepare future apparel professionals to be properly equipped with new technology development?

\section{Materials and methods}

\section{Methods}

A case study approach was used to gain understanding of students' perception and learning enhancement through using $2 \mathrm{D}$ and $3 \mathrm{D}$ software programs. The case study provides insight into issues regarding particular traits, characteristics, or problems Kawamura. ${ }^{13}$ According to Yin $^{14}$ cited in Baharein \& Noor, ${ }^{15}$ a case study is "an empirical inquiry that investigates a contemporary phenomenon within its real life context using multiple sources of evidence" (p.1602). Furthermore, a well-chosen case study will help achieve competence in a learning environment, especially with respect to teaching Flyvbjerg. ${ }^{16}$ Therefore, to understand and examine the processes of students' perception and learning through using 2D and 3D software programs, a case study method was chosen for this study. In addition to surveying students' perceptions while using 2D and 3D software programs for their design skill development, classroom observation by an instructor was also used as a part of the case study approach The use of participant observation allows for insights into context, relationships, and behavior of the subject. Moreover, observation can provide information previously unknown to researchers that are crucial to project data, data collection, and interpretation of other data Flyvbjerg. ${ }^{16}$

The participants were recruited from a population of fashion design students enrolled in an upper-level patternmaking class in a large public university in Midwestern United States. Participants were given five weeks to complete their design projects using $2 \mathrm{D}$ and $3 \mathrm{D}$ software programs. After projects were completed, the questionnaire was distributed in the form of take-home assignment for participants to answer various aspects of how 2D CAD patternmaking and 3D garment simulation software enhanced their learning outcomes for design processes. Researchers developed questions in three categories related to use of 2D patternmaking software, use of 3D models in the early stages of the apparel design process, and evaluating CAD programs.

\section{Settings}

The stated objective of this course project as a part of the case study method was to teach students use of the 2D patternmaking software program to create a production garment for a number of apparel markets. Additional 3D garment simulation software was introduced to students, allowing them to perform $3 \mathrm{D}$ garment simulation to analyze fit to the body using a 3D virtual model avatar. Our goal for this project was to teach students how to simultaneously use two software programs for their design development, making them able to effortlessly adapt to any type of patternmaking software during their future transition into the fashion industry.

To understand foundational knowledge and skills in 2D patternmaking and 3D garment simulation techniques, students learned to use different types of tools provided by the $2 \mathrm{D}$ CAD patternmaking program to draft advanced patterns by completing inclass assignments during the first five weeks. They also learned to create a spec pack and marker using the 2D patternmaking program, allowing them to understand the product development process in general. During the fifth week of class, students learned to use a 3D garment simulation program where they were able to reproduce physical properties of fabrics and visualize the way they draped in real life. Students seemed excited that they were able to virtually sew and see $3 \mathrm{D}$ finished products without cutting and sewing actual fabric when they were using 3D garment simulation program.

\section{Case study method}

As mentioned above, both survey of student attitudes and perceptions and instructor observation were used in a case study approach to assess using $2 \mathrm{D} \mathrm{CAD}$ and $3 \mathrm{D}$ visual prototyping tool as a learning enhancement tool for an advanced pattern development class. By collecting survey data from students in the form of both a 5-point Likert scale and open-ended questions, this study was able to gather both qualitative and quantitative data regarding student attitudes and perceptions using 2D and 3D software programs for their pattern design development in the classroom.

\section{Questionnaire}

The survey questionnaire consisted of two parts:

a. Participants' background information about general design skills

b. Evaluation of both CAD programs in terms of participants' apparel design processes.

For the first part, questions regarding participants' skill level in apparel design, pattern drafting, and experience with CAD program were asked to rate on a 5-point Likert scale ranging from poor to excellent. "How long ago did participants start learning the 2D patternmaking program?" was asked, yielding ratings ranging from '1-2 years ago' to 'more than 8 years ago'. "Whether learning to use a $2 \mathrm{D}$ patternmaking and $3 \mathrm{D}$ garment simulation programs have influenced participants designing capability" was also asked, with 'Yes' and 'No' answers with asking for explanation. For evaluation of using both 2D and 3D CAD programs, participants were asked:

A. "During the design process, did using 2D patternmaking software help them", with answer options 'understand my design 
better',' understand my pattern better', 'communicate my ideas to others', 'express my ideas better', 'understand the design brief', 'straighten up my pre-conceptual idea', and 'identify design problems successfully'.

B. "Did using both $2 \mathrm{D}$ patternmaking software and $3 \mathrm{D}$ garment simulation within their conceptual design affect their work positively?" was answers rated on a 5-point Likert scale ranging from 'Strongly disagree' to 'strongly agree'.

C. "How important was it to create a 3D model (physical or digital) early in their design process?" was asked with answers on a 5-point Likert scale ranging from 'Very Unimportant' to 'Very Important'.

D. "In which stages of the conceptual design process would they use creating 3D garment simulation models?" was asked with possible answer options, 'Design brief analysis', 'Outline design', 'Final sketch Design', and 'none or other phrases to specify'.

E. Finally, the following questions were asked as open-ended questions. "In which ways did using 2D/3D software affect their work?; "What was the most helpful aspect of using 2D/3D software?"; "What was the least helpful aspect of using 2D/3D patternmaking software?"; "How important was learning about the 2D and 3D patternmaking software to them as designers?"

\section{Results and discussion}

\section{Results}

The findings gathered in this article were developed from a small sample group $(n=13)$. Twenty questions were submitted to participants $(n=13)$ to discover how use of $2 \mathrm{D}$ and 3D CAD programs enhanced student learning outcomes and student perception of using such programs.

General designing skills: Most participants had a 'Very Good' $(53.8 \%, \mathrm{n}=7)$ or 'Good' $(38.4 \%, \mathrm{n}=5)$ skill level in apparel design and their skill level in pattern drafting was also 'Very Good' $(46.1 \%, \mathrm{n}=6)$ or 'Good' (38.4\%, n=5); two students rated only 'Fair' (Figure 1).

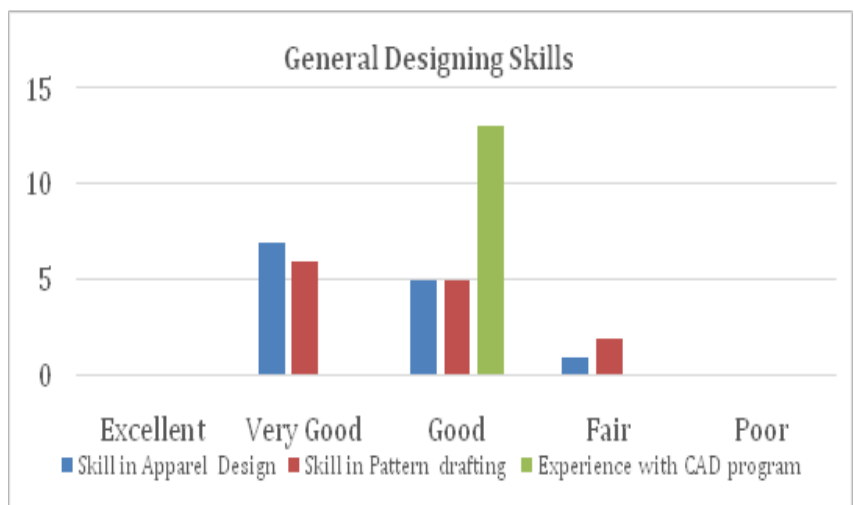

Figure I General Apparel Designing skills.

CAD skills: All participants had a 'Good' (Basic 2D\& 3D) level of experience with CAD programs. The majority of the participants $(84.6 \%, \mathrm{n}=11)$ indicated they started learning $2 \mathrm{D}$ patternmaking program '1-2 years ago' while two participants indicated '2-4years ago'.

CAD programs influence on design capability: When asked if the $2 \mathrm{D}$ patternmaking and the $3 \mathrm{D}$ garment simulation program has influenced their design capability, 11 students (84.6\%) said 'yes' with respect to the 2D patternmaking program and 9 students (69.2\%) said 'yes' with respect to the 3D garment simulation program (Figure 2). Most participants rated the 2D CAD program quality in general as 'Very Good' ( $84.6 \%, \mathrm{n}=11)$ and 3D the garment simulation as 'Good' $(72.7 \%, \mathrm{n}=8)$.

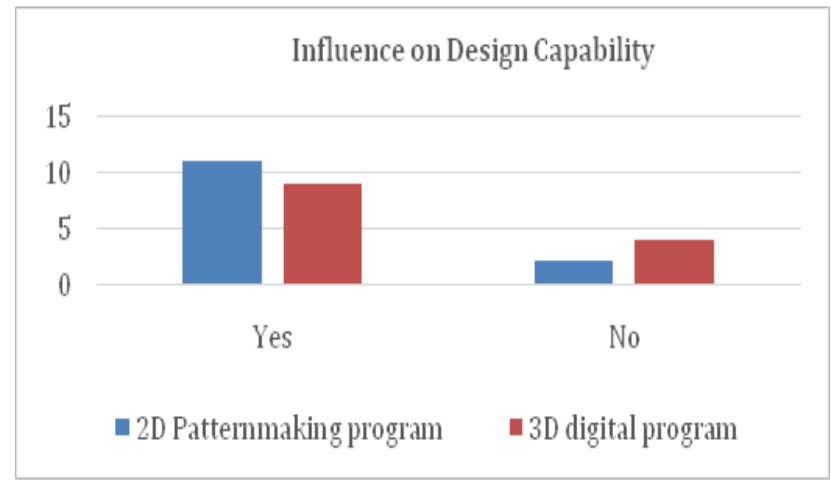

Figure 2 Computer programs influence on design capability.

Using 2D software program during the design process: With respect to 2D patternmaking software, out of the 13 students, $77 \%$ $(\mathrm{n}=10)$ responded that the $2 \mathrm{D}$ patternmaking software helped them to better understand their pattern. More than half the students $(69 \%, n=9)$ indicated that it helped them to successfully identify design problems, and more than half $(54 \%, \mathrm{n}=7)$ pointed out that it both helped them to understand their design better and clarify their pre-conceived ideas $(54 \%, n=7)$. Furthermore, about $62 \%(n=8)$ of participants indicated either 'agree' or 'strongly agree' that using 2D patternmaking-software in their conceptual design positively affected their work (figure 3 ).

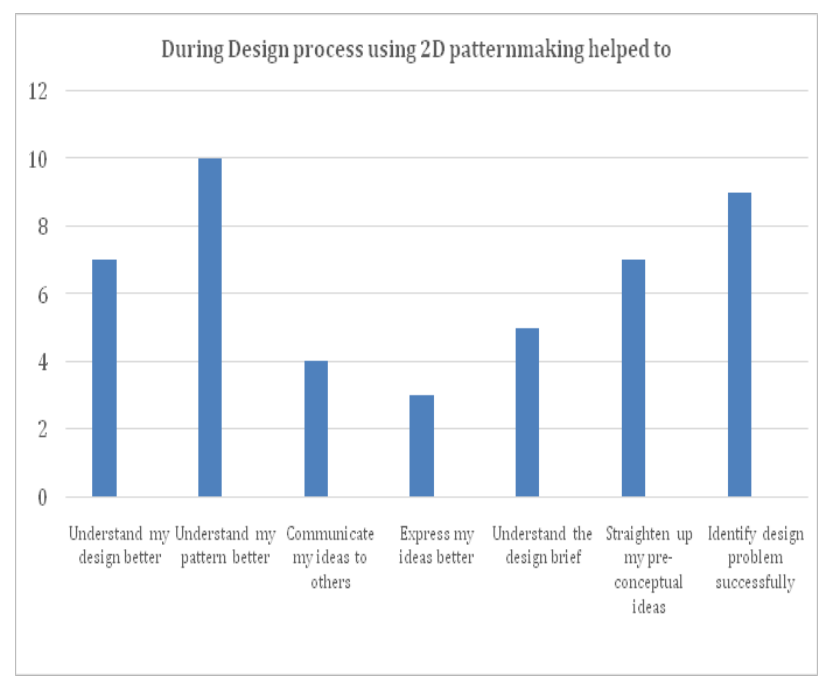

Figure 3 Using 2D Patternmaking during Design Process.

Using 3D during the design process: With respect to the 3D garment simulation program, more than half $(65 \%, n=8)$ of the students also indicated that creating a 3D model (either physical or digital) early in their design process was very important to them. About half of them indicated that they would create $3 \mathrm{D}$ virtual models during a "design brief analysis" stage $(46 \%, \mathrm{n}=6)$ while a few answered similarly with respect to a "outline design" stage $(38 \%, \mathrm{~N}=5)$ (figure 4). 


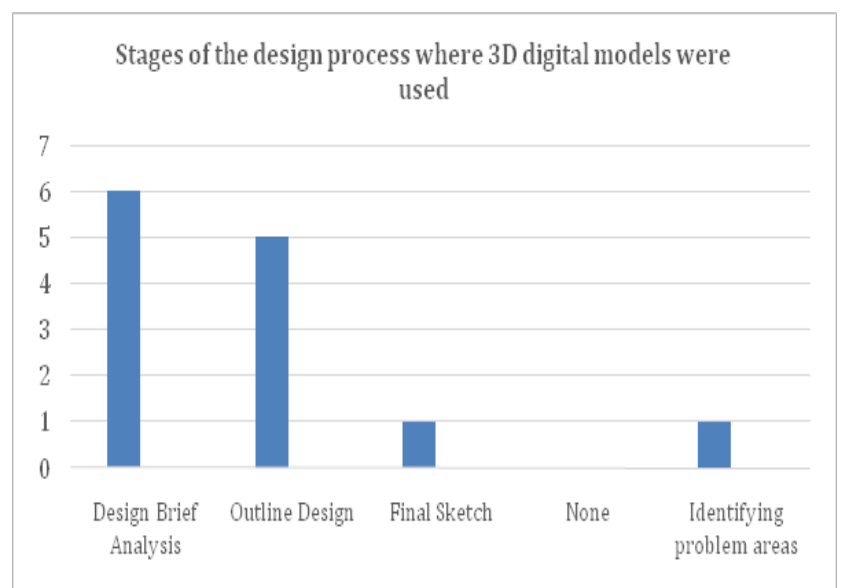

Figure 4 Stages of the design process where 3D digital models were used.

Helpfulness of using 2D program: Students perceived the 2D patternmaking program to be useful, and it positively affected their design work because of its flexibility that provided multiple ways for pattern adjustment, reduced the time taken in altering patterns, and made editing and adding seam allowances easier. The following comments were made by students when they were asked how the 2D patternmaking program affected their design work. "Helps me to visualize pattern problems and it is easier to fix problems using the 2D patternmaking software", "It was helpful to see everything together on one screen. With paper patterns, it is easy to lose them, rip them, and sometimes they are huge on one screen. Everything is more organized and easy to work with.", and "Easier to make changes without re-cutting paper". When asked what was most helpful in using the 2D pattern-making program, students made the following comments. "The ease of editing patterns and adding seam allowances as well as manipulating dart positions. Also you are able to get exact measurement much easier.", "Use of less paper, easy fixes instead of having to trace everything over again measuring is easier too.", and "Being able to change move something and put it back if I don't like it."

Several students commented that getting comfortable in using the $2 \mathrm{D}$ program was the least helpful part of the process, and some students commented that developing accurate fit or a draped garment was difficult when using the 2D patternmaking program. "Too many buttons", "Difficult to navigate zoom in/out", and "Since it is on the computer, it is more difficult to get an accurate fit."

Helpfulness of using 3D program: With respect to the 3D program, students commented that allowing them to see virtual fit on a body helped them to rethink their designs, to identify fit and pattern problems/issues, and to visualize the overall look of their designs. The following comments were made about the 3D program, "It gives you a better idea of how it looks on a body. You can figure out if it is tight or loose in certain areas and how it will be sewn", "Seeing how it all pieced together initially. In case a portion may have been difficult to sew, it was a good initial lesson on where everything should go", "It was nice to see it digital made and how well it would fit the body. Made easy to rethink my design", "It is important to see the fit, especially for me, because I struggle with this sometimes, so if I can get an initial fit it makes working in the final fabric go much smoother", "It inspires a lot of my design and drapes", and "I can see my design on a human body. It gives me an idea of what will/won't work about my design".
Students reported that the most helpful parts of using the 3D garment simulation program were finding fitting problems easily, planning sewing steps, and reducing use of pins and fabric. "It is easy to start over or go back without having to deal with pins", " It was helpful when it came to draping the first muslin, not having to execute fabric", and "I could find my problem areas easy".

Students reported that the least helpful parts of using the $3 \mathrm{D}$ garment simulation program were understanding and using the program and achieving accurate measurement and fit; a few students simply preferred the physical touch of fabric over using a computer. "It was difficult to get accurate measurements between the avatar and the dress form", "I personally enjoy touching the fabric. I feel like I have more control in real life", "Trying to learn everything, all the shortcuts, reading upon why something didn't work", and "Understanding all the shortcuts and buttons".

Using 2D and 3D in the fashion industry: Nearly all students commented that using both a $2 \mathrm{D}$ and a $3 \mathrm{D}$ CAD program would be extremely important for future work in the fashion industry. The following comments are from students regarding using both programs in the fashion industry. "I think its great knowledge to have. It's the future of the fashion industry. I feel more confident going for a job saying I have experiences it", "I think it is very important. I would have definitely used it throughout school if I had known about it. It is a great software to have to change basic patterns and make quick patterns", "Very important now that the industry is very focused on computer programs in the workforce", and "I think it is a really good skill to know, especially since fashion seems to be moving in a digital direction".

Perceptions toward learning 2D and 3D programs during the design process: Students perceived that learning to use the $2 \mathrm{D}$ and 3D CAD programs influenced their design capability more positively than negatively. There were only a couple of negative comments.

Positive comments: "Understand pattern better", "Has just broadened my knowledge", "I love 2D patternmaking software, so easy to use and made my work go much faster and smoother", "It lets me think how to draft faster and better", "Has given me more knowledge and experience".

Negative comments: “I don't think I would learn this software that much when it comes to designing", "I felt it put me behind I was hoping to get a good initial fit before the actual garment, but I had to fix so many patterns that I wished I would have gone straight to a muslin in fabric rather than digital".

Classroom observations: The instructor observations in the classroom reveal that students were significantly more challenged working with the $3 \mathrm{D}$ program than with the $2 \mathrm{D}$ program. Overall, students in the course were observed working diligently and being on task when they were working with either the 2D patternmaking or the 3D garment simulation program. With respect to classroom instructional interaction, students were observed to be working significantly more independently with the $2 \mathrm{D}$ program than with the 3D program. Students were observed to be working significantly less independently when they used the $3 \mathrm{D}$ program compared to using the 2D program. Moreover, students were observed to be interacting with their peers for instructional purposes significantly more when using the $3 \mathrm{D}$ program than using the $2 \mathrm{D}$ program. Because there was more peer interaction, student was observed to be in small-group settings 
when they used the 3D garment simulation program. Students were observed to have significantly more instructional interaction with the professor when working with the 3D program compared to working with the 2D program. Finally, it was observed by the instructor that students seemed to be faced with more challenges using 3D simulations to accurately analyze the fit by connecting the $3 \mathrm{D}$ virtual model to an actual dress form, given that the computer screen only displayed in $2 \mathrm{D} \cdot{ }^{17-23}$

\section{Conclusion}

This paper provides information and insight regarding use of threedimensional concepts in using 2D CAD patternmaking software and $3 \mathrm{D}$ garment simulation in advanced patternmaking class. The specific purpose of this paper was to address the advantages of using a 3D garment simulation program in an upper-level patternmaking course for fashion design students. With rapid technology development in the fashion industry, it is critical to incorporate state-of-the-art technology into design class projects to help students become strong candidates for positions in the fashion industry. Learning 2D CAD patternmaking software and a 3D garment simulation program will especially help them be prepared with future sustainability practices because the digital processes can reduce time, sample production costs, and transportation requirements. It both helped students be more efficient with the pattern development process and encouraged them to think more critically about their design process. The results from the study clearly indicated that the $2 \mathrm{D}$ patternmaking software increased and enhanced both performance and creativity by making it possible to save time by creating and drafting designs with just a few clicks, and assisting students in creating and modifying their designs without going through drastic changes. The result of this study demonstrated that, by using $3 \mathrm{D}$ garment simulation, students were able to test the fit and their overall design concept as well as aesthetics. These findings are quite similar to those from previous studies by Peterson, et al., (2015) showing that 3D visualization as a learning tool has helped improve student learning and transfers a better understanding of the subject matter. Students were also able to identify construction issues and overall enhance their pattern learning processes using both $2 \mathrm{D}$ and 3D patternmaking software tools.

Collective student attitude towards both 2D and 3D CAD programs was overall positive compared to that related to traditional manual methods. Students seemed to enjoy using computer programs to develop their patterns because this allows them to reduce the time required for adding seam allowances and manipulating patterns, thereby saving papers and pins. Students seem to appreciate going back and forth to make edits to their patterns when they identify fitting or pattern issues.

The result of this study also showed that students seemed to perceive using the $2 \mathrm{D}$ patternmaking program more positively than using the $3 \mathrm{D}$ garment simulation program. This may be due to the fact; they spent more time in the classroom learning the 2D program compared to learning the $3 \mathrm{D}$ program and thereby became more familiar with using the $2 \mathrm{D}$ program. In addition, the 3D garment simulation program that was used in this study was a somewhat recently developed program and some of the complicated designs created by students were difficulty to simulate. Moreover, since the 2D and the 3D program were developed by two different companies, it was hard to make an easy transition between the two programs and students sometimes had to learn new tools and tricks when switching between the two programs. Although the $2 \mathrm{D}$ patternmaking program has been around longer than the 3D garment simulation, this study suggests that patternmaking computer software companies should work on creating programs with better transition between 2D and 3D garment simulations and modelling. Furthermore, more established 3D garment-simulation software should be developed because students have commented that there were some discrepancies between avatar and dress form in terms of fit and measurements.

It is also obvious from student responses that they are clearly aware that digitization of the design process in the fashion industry is already happening and quickly moving forward. Although, using a $3 \mathrm{D}$ garment simulation program in the classroom has been common practice in fields such as medicine, architecture, and science, little to no research has done on such use in fashion classes. This study helped students understand that 3D garment simulation will reduce the sample production time from days to weeks and perhaps even more. This study certainly contributes to the body of research in using both $2 \mathrm{D}$ and 3D CAD programs in the classroom by addressing their advantages in creating effective learning environment for improving students' technical design learning experiences. This study also proves that teaching both 2D and 3D CAD program will help fashion design students to be better-equipped to become successful professionals in the competitive fashion industry.

\section{Limitations and suggestions for future studies}

This study was not without limitations. Because we aimed to gather responses from students who had previously used 2D CAD patternmaking and 3D simulation programs in the apparel design classroom, the current sample is based on convenience samplings techniques, prohibiting the generalization of the findings. However, the findings of the study provide directions for future research in exploring and assessing fashion design students learning processes when using computer programs for developing their designs and offer insights to educators and programmers involved in the apparel design field. Possible future research could replicate the study with larger samples and assess different learning processes using other computer programs used for apparel design development in the classroom.

\section{Acknowledgements}

None.

\section{Conflict of interest}

a. This manuscript is original work, and has not been copyrighted or published previously.

b. No other financial support or incentive has been provided for this manuscript.

c. I am one author signing on behalf of all co-author of this manuscript.

\section{References}

1. Chase RW. CAD for Fashion Designers. UK: Prentice-Hall Inc, 1997.

2. Sayem ASM, Kennon R, Clarke N. 3D CAD system for the clothing industry. International J Fashion Design, Technology \& Education. 2010;3(2):45-53.

3. Fontana M, Rizzi C, Cugini U. 3D virtual apparel design for industrial applications. Computer Aided Design. 2005;37(6):609-622.

4. Puri A. Efficacy of pattern making software in product development. International J Advanced Quality Management. 2013;1(1):21-39. 
5. Abecassis-Moedas $\mathrm{C}$. Integrating design and retail in the clothing value chain- an empirical study of the organization design. International $J$ Operations \& Production Management. 2006;26(4):412-428.

6. Optitex. Our Customers. 2017.

7. Perdomo JL, Shiratuddin MF, Thabet W, et al. Interactive $3 \mathrm{D}$ visualization as a tool for construction education. ITHET 6th Annual International Conference. Santo Domingo, Juan Dolio, Domanican Republic. 2005.

8. Haque ME. Contemporary techniques to teach reinforced concrete design, proceedings of the 2002 American Society for Engineering Education (ASEE) Gulf-Southwest Annual Conference. The University of Louisiana at Lafayette, Louisiana, USA; 2002.

9. Barkand J, Kush J. GEARS a 3D virtual learning environment and virtual social and educational world in online secondary schools. Electronic J 3-Learning. 2009;7(3):215-224.

10. Bronack S, Sanders R, Cheney A, et al. Presence pedagogy: Teaching and learning in a 3D virtual immersive world. International J Teaching \& Learning in Higher Education. 2008;20(1):59-59.

11. Huang HM, Rauch U, Liaw SS. Investigating learners' attitude toward virtual reality learning environments: Based on a constructivist approach. Computer \& Education. 2010;55(3):1171-1182.

12. Monahan T, McArdle G, Bertolotto M. Virtual reality for collaborative e-learning. Computer \& Education. 2008;50(4):1339-1353.

13. Kawamura Y. Doing Research in Fashion and Dress: An Introduction to Qualitative Methods. New York: Berg Publication; 2011. p. 150.
14. Yin R. Case Study Research: Design and Methods (Applied Social Science Research Method). California: Sage Publication; 1989. p. 1-28.

15. Baharein K, Noor M. Case Study: A Strategic Research Methodology. American J Applied Sciences. 2008;5(11):1602-1604.

16. Flyvbjerg B. Five misunderstandings about case-study research Qualitative Inquiry. 2006;12(2):219-245.

17. Clarke P, Wilhelm W. 3D in apparel design: a revolution in the industry. 2011.

18. Fixson SK, Marison T. Back-loading: A potential side effect of employing digital design tolls in new product development. J Product Innovation Management. 2010;29(1):140-156.

19. Henard D, Szymanski D. Why some new product are more successful than others. J Marketing Research. 2001;38(3):362-375.

20. Liu Y, Zhang D, Yuen MM. A survey on CAD methods in 3D garment design. Computers in Industry. 2010;61(6):576-593.

21. Malhotra MK, Heine ML, Grover V. An evaluation of the relationship between management practices and computer aided design technology. J Operations Management. 2001;19(3):307-333.

22. McNally RC, Akdeniz MB, Calantone RJ. New product development process and new profitability: Exploring the mediating role of speed to market and product quality. J Product Innovation Management. 2011;28(1):63-67.

23. McGregor L. Optitex pairs with PTC to speed up apparel design process. Sourcing Journal. 2016 